\title{
A Practical Experience About Dynamic Performance and Stability Improvement of Synchronous Generators
}

Chi-Jui Wu

Professor, Department of Electrical Engineering, National Taiwan University of Science and Technology, Taipei, Taiwan 106, R.O.C., cjwu@mouse.ee.ntust.edu.tw

Yung-Sung Chuang

Graduated student, Department of Electrical Engineering, National Taiwan University of Science and Technology, Taipei, Taiwan 106, R.O.C.

Follow this and additional works at: https://jmstt.ntou.edu.tw/journal

Part of the Electrical and Computer Engineering Commons

\section{Recommended Citation}

Wu, Chi-Jui and Chuang, Yung-Sung (2003) "A Practical Experience About Dynamic Performance and Stability Improvement of Synchronous Generators," Journal of Marine Science and Technology. Vol. 11: Iss. 3, Article 5. DOI: $10.51400 / 2709-6998.2279$

Available at: https://jmstt.ntou.edu.tw/journal/vol11/iss3/5

This Research Article is brought to you for free and open access by Journal of Marine Science and Technology. It has been accepted for inclusion in Journal of Marine Science and Technology by an authorized editor of Journal of Marine Science and Technology. 
A Practical Experience About Dynamic Performance and Stability Improvement of Synchronous Generators

Acknowledgements

The authors would like to express their sincere thanks to people in Tong-Shiao Generation Station for help in this work. 


\title{
A PRACTICAL EXPERIENCE ABOUT DYNAMIC PERFORMANCE AND STABILITY IMPROVEMENT OF SYNCHRONOUS GENERATORS
}

\author{
Chi-Jui Wu* and Yung-Sung Chuang**
}

Key words: synchronous generator, static excitation system, dynamic performance, dynamic stability, parameter identification.

\begin{abstract}
This paper describes the practical experiences about the no-load dynamic performance test, parameter identification, and tuning of static excitation systems (SESs) of the synchronous generators in the Tong-Shiao Generation Station of the Taiwan Power System. The dynamic stability of under-load generators has also been improved. The hardware circuits of SESs had been modified. This caused the detuning of parameter values, so that the generators did not have enough ability to sustain voltage fluctuation disturbances. Several SESs had been preliminarily retuned according to the results from simple field tests. However, step signal responses in field tests revealed that the characteristics of some units were different from the computer simulation results. Before retuning them again, it needed to identify the parameters of SESs. The least-squared-error algorithm has been employed to estimate the parameters of inner-loop regulators in SESs. Then SESs have been retuned again to have good dynamic performance indices. Eigenvalue analysis and time domain simulation were used to examine the dynamic stability conditions of underload generators. The experiences and results in this paper provide useful references about performance improvement of generators.
\end{abstract}

\section{INTRODUCTION}

In the study of this paper, the Tong-Shiao Generation Station of the Taiwan Power System had six combined-cycle generation units with a total capacity of $1716 \mathrm{MW}$. Both static excitation systems (SESs) and brushless rotating excitation systems are employed. Since of the shortage of area generation capacity, these units also have to operate in off-peak period at night. A 69-kV feeder connected to the station bus serves three large electric arc furnace (EAF) customers. The EAFs only work during off-peak period but cause continuous

Paper Submitted 08/28/03, Accepted 10/01/03. Author for Correspondence: Chi-Jui Wu.

*Professor, Department of Electrical Engineering, National Taiwan University of Science and Technology, Taipei, Taiwan 106, R.O.C.

E-mail: cjwu@mouse.ee.ntust.edu.tw.

**Graduated student, Department of Electrical Engineering, National Taiwan University of Science and Technology, Taipei, Taiwan 106, R.O.C. voltage fluctuation disturbances. This had ever activated the $\mathrm{V} / \mathrm{Hz}$ protection relays of the SESs and tripped the generators. A field measurement of the SESs showed that the SESs did not have enough damping because the hardware circuits of SESs had been modified. The SESs had been preliminarily retuned to improve the dynamic performance [14]. However, the field test responses of some units were different from computer simulation results. The actual performance conditions needed to be checked again, and SESs parameters needed to be identified.

The small signal test method [3,8] with time domain responses is a good method to examine the dynamic performance of an excitation system of a generator under no-load. The method is to inject a small step signal into the excitation system, and then the performance condition is examined from the responses of terminal voltage. The results can be compared with the recommendation values in the IEEE Standard 421.2 [3]. It also recommends that an SES should be tested at least every five years. Computer simulations have to be compared with the field measurements as well. Parameters of SESs must be identified if the comparison shows non-allowable difference. Several approaches about parameter identification and dynamic performance improvement of excitation systems had been given in the literature. An excitation control system had been tested on a single generator-infinite bus system with the simulation results showing excellent damping of power swings and retaining good voltage control [10]. The method to fit complex frequency-response data to a rational transfer function was obtained by an online identification algorithm [7]. The recursive least square time-domain identification was employed to identify the parameters of a synchronous machine model [11]. The modified least-squared-error approach with a coherence function was developed to determine parameters of exciters [9]. In [12], a step input voltage test was performed to estimate the parameters of time constant models and equivalent circuit models. An identification procedure for a hydro-generator plant using an adaptive technique was investigated [13]. The variable 
parameters of a synchronous machine were estimated using an on-line adaptive algorithm [15].

Before the mitigation of voltage flicker disturbances, it is still required that generators in TongShiao have enough damping of power oscillations. The parameter values of the excitation systems must be well known so that the performance conditions are ensured. In this paper, a step signal was injected into the SESs to test the dynamic performance. The responses of noload generator terminal voltages were surveyed. The voltage responses provided information of overshoot, rise time, settling time and damping ratio to confirm the performance conditions. The test results have been compared with the IEEE Standard 421.2. Some differences appeared between field tests and computer simulations. A least-squared-error algorithm was also used to identify the inner-loop regulator parameters of the SESs. Then the SESs were retuned again. Accuracy of simulation results with true parameter values is satisfactorily confirmed by comparing with the field measurements. It could be concluded that the SESs with final parameter values should have enough ability to sustain the disturbances of voltage fluctuation.

\section{SYSTEM UNDER STUDY}

The one-line diagram of the Tong-Shiao Generation Station under this study is shown in Fig. 1. Each combined-cycle generation unit consists of two or three 60-MVA gas turbine (GT) generators and one 100MVA steam turbine (ST) generator. The excitation systems of GT generators in unit 1 and unit 2 are of static type with analog controllers and belong to the IEEEST3A model [4]. The two ST generators are equipped with digital static excitation systems. All generators of units 3-5 are equipped with brushless rotating excitation systems. The digital static excitation systems are also used in unit 6. The SES, as shown in Fig. 2, consists of an automatic voltage regulator (AVR), a transient gain reduction (TGR) element, an inner loop regulator,

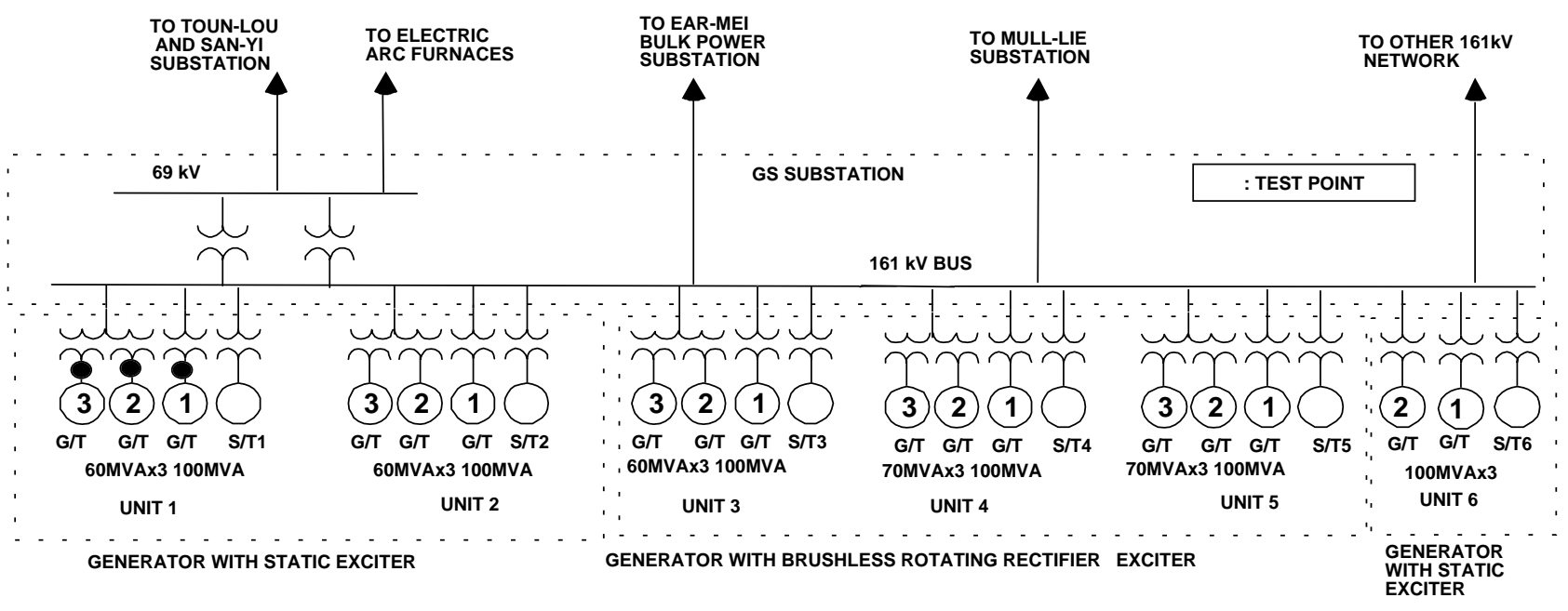

Fig. 1. One-line diagram of Tong-Shiao Generation Station.

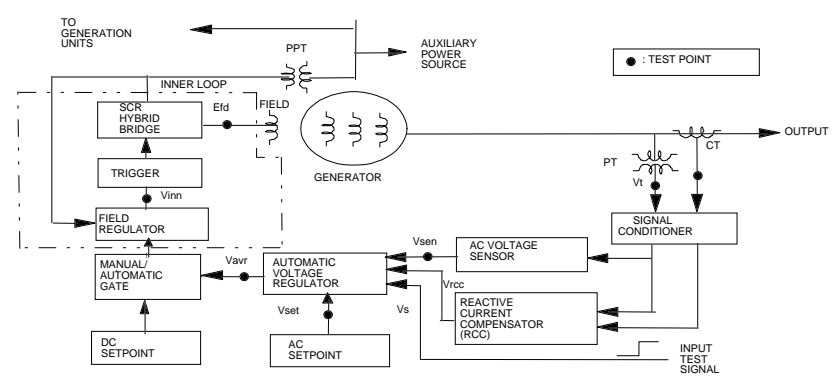

Fig. 2. SES block diagram and field test points.

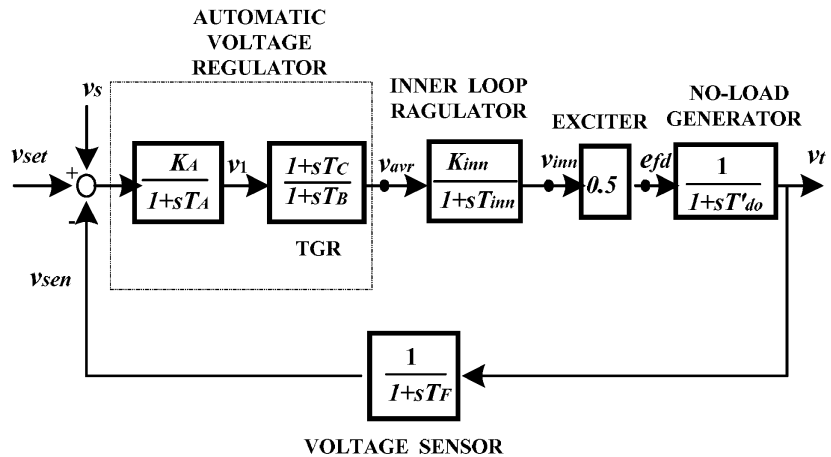

Fig. 3. Equivalent SES block diagram of a generator at no-load. 
a reactive current compensator ( $\mathrm{RCC}$ ), and a static exciter. Since the generators are connected through transformers, the RCC is not used. Figure 3 shows the SES block diagram with equivalent transfer functions for the generator at no-load. The EAF plants are fed from the generation station (GS) $69 \mathrm{kV}$ bus.

The six generators considered in this paper are the GT type in units 1 and 2, which are identical. Table 1 gives the original parameter setting of generator 1-1. The original parameters were obtained from the equipment manual. Figure 4 shows the field recording of active and reactive power outputs of generator 1-1 with original parameter setting. When the EAFs were in

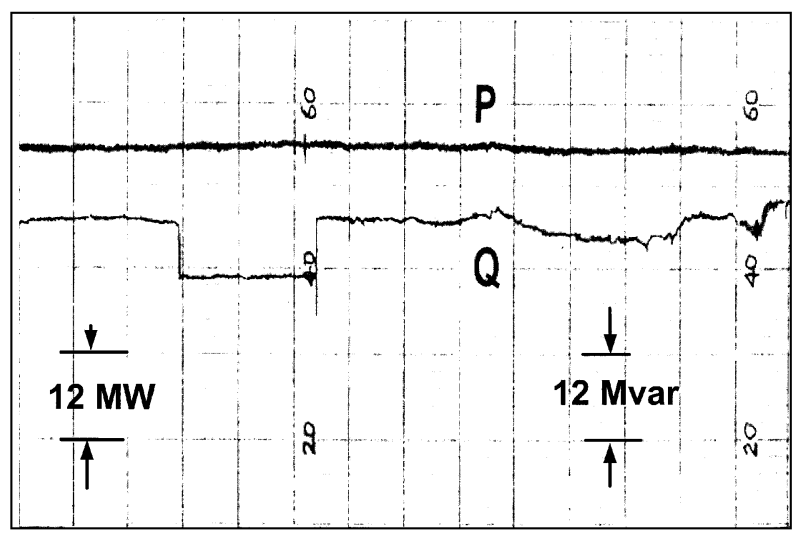

TIME (20MIN/DIV)

(a)

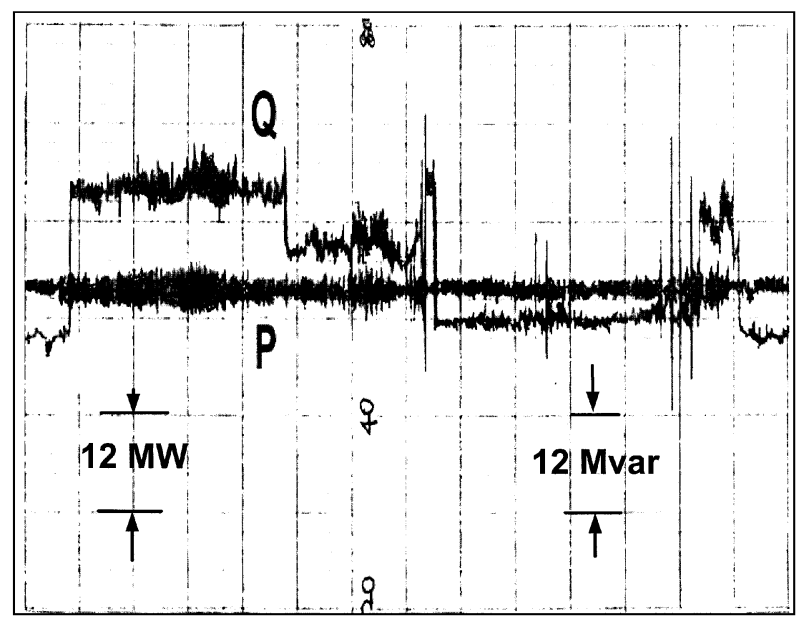

TIME (20MIN/DIV)

(b)

Fig. 4. Recorded powers of generator 1-1 with original setting of excitation system (a) day time; (b) night time. operation, reactive power variation in the 60-MVA generator could reach up to $40 \mathrm{Mvar}$. The power factor can be as low as 0.7. More severe voltage fluctuation had ever activated the $\mathrm{V} / \mathrm{Hz}$ protection relays of SESs. The SESs of six GT generators had been forced to manual operation (open-loop voltage regulation) mode. Therefore the improvement of SESs performance was necessary. The temporary parameters were obtained after evaluating the frequency domain Bode plots of SESs according to IEEE Standard 421.2. Table 1 also gives the temporary parameter setting. The record in Fig. 5 reveals that the generator has better reactive power response compared with Fig. 4. The temporary parameter setting was also employed in other GT generators of units 1 and 2 . However, their dynamic performance must be checked carefully again.

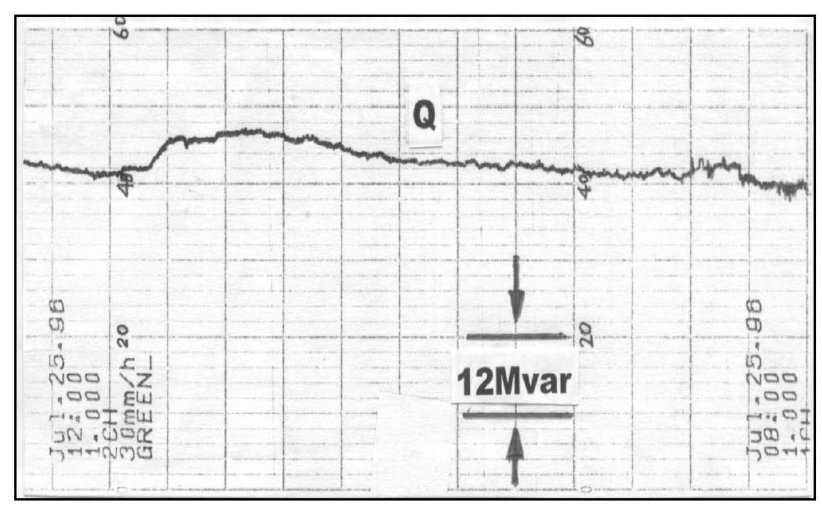

TIME (20MIN/DIV)

(a)

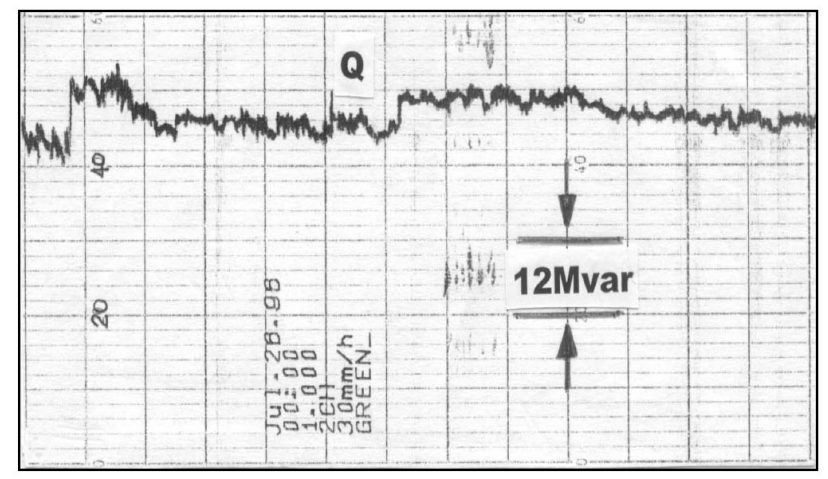

TIME (20MIN/DIV)

(b)

Fig. 5. Recorded reactive power of generator 1-1 with temporary setting of excitation system (a) day time; (b) night time. 


\section{DYNAMIC PERFORMANCE TEST METHOD}

The dynamic performance test considers the voltage responses of no-load generators with excitation systems. In field tests, the small signal method with time domain responses is used [3]. A no-load generator means at synchronous speed and rated voltage but is not connected to the power system. For the system in Fig. 2 , a $1 \%$ small step signal can be injected into the excitation system reference voltage terminal, and then the dynamic performance is examined by the responses of generator terminal voltage. The dynamic performance response of a second-order system subjected to a step input signal is shown in Fig. 6, where the performance indexes include rise time, overshoot, and settling time. The other index, damping ratio $\zeta$ can be calculated from the overshoot:

$$
\text { Overshoot }=e^{-\xi \pi / \sqrt{1-\xi^{2}}}
$$

The field test results could be compared with the recommendation values in the IEEE Standard 421.2 to verify the performance conditions.

The results from field tests and computer simulations must be compared not only for the performance conditions but also for accuracy of system parameter values. In computer simulations, the Runge-Kutta method is used. For the equivalent system shown in Fig. 3 , five first-order differential equations are used.

$$
\begin{aligned}
\frac{d v_{1}}{d t}= & \frac{-1}{T_{A}} v_{1}-\frac{K_{A}}{T_{A}} v_{s e n}+\frac{K_{A}}{T_{A}} v_{s e t}+\frac{K_{A}}{T_{A}} v_{s} \\
\frac{d v_{a v r}}{d t} & =\left(\frac{1}{T_{B}}-\frac{T_{C}}{T_{B} T_{A}}\right) v_{1}-\frac{1}{T_{B}} v_{a v r}-\frac{T_{C} K_{A}}{T_{B} T_{A}} v_{s e n} \\
& +\frac{T_{C} K_{A}}{T_{B} T_{A}} v_{s e t}+\frac{T_{C} K_{A}}{T_{B} T_{A}} v_{s} \\
\frac{d v_{i n n}}{d t} & =\frac{K_{i n n}}{T_{i n n}} v_{a v r}-\frac{1}{T_{i n n}} v_{i n n}
\end{aligned}
$$

Table 1. Parameter setting of excitation system of generator 11

\begin{tabular}{cccc}
\hline & $\begin{array}{c}\text { Original } \\
\text { setting }\end{array}$ & $\begin{array}{c}\text { Temporary } \\
\text { setting }\end{array}$ & $\begin{array}{c}\text { Final } \\
\text { setting }\end{array}$ \\
\hline$K_{\min }$ & 14 & 7 & 8.01 \\
$T_{B}(\mathrm{sec})$ & 2.5 & 7 & 10 \\
$T_{C}(\mathrm{sec})$ & 0.25 & 1 & 1 \\
$T_{A}(\mathrm{sec})$ & 0.001 & 0.001 & 0.001 \\
$T_{\min }(\mathrm{sec})$ & 0.28 & 0.28 & 0.0516 \\
$T_{F}(\mathrm{sec})$ & 0.003 & 0.003 & 0.003 \\
$K_{A}$ & 105 & 105 & 50 \\
\hline
\end{tabular}

$$
\begin{aligned}
& \frac{d v_{s e n}}{d t}=\frac{-1}{T_{F}} v_{s e n}+\frac{1}{T_{F}} v_{t} \\
& \frac{d v_{t}}{d t}=\frac{0.5}{T_{d o}^{\prime}} v_{i n n}-\frac{1}{T_{d o}^{\prime}} v_{t}
\end{aligned}
$$

A $1 \%$ step signal, $v_{s}$, can be injected to the reference voltage input of SES in Fig. 3, and the response of generator terminal voltage is used to reveal the dynamic performance.

\section{DYNAMIC PERFORMANCE TEST RESULTS}

The SES dynamic performances of three unit-1 GT generators were examined. The voltage responses of generators $1-1,1-2$, and 1-3 in field tests and computer simulations are shown in Fig. 7. At field tests, the system goes to steady state after 1-2 oscillation cycles. The performance indexes of voltages are shown in Table 2. The values of rise time, overshoot, damping ratio, and settling time should be compared with the IEEE 421.2. In field tests, generator 1-2 and generator 1-3 are more similar, and their values satisfy the IEEE 421.2. However, generator $1-1$ is different with other generators. The rise time, 0.08 second, is out of the recommendation value.

\section{PARAMETER IDENTIFICATION OF EXCITATION SYSTEM}

Before retuning of SESs, their parameters should be identified. According to the manual, values of gain $K_{A}$ and time constants $T_{A}, T_{B}$, and $T_{C}$ can be easily examined by checking the control card, which consists of analog electronic circuits. Their values are the same as those temporary setting values listed in Table 1.

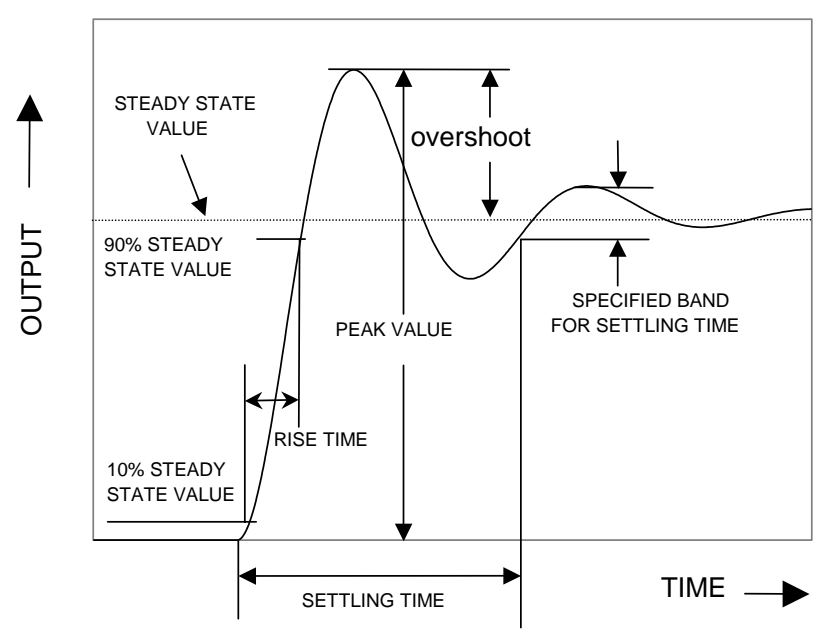

Fig. 6. Response of a second-order system subjected to a step signal. 


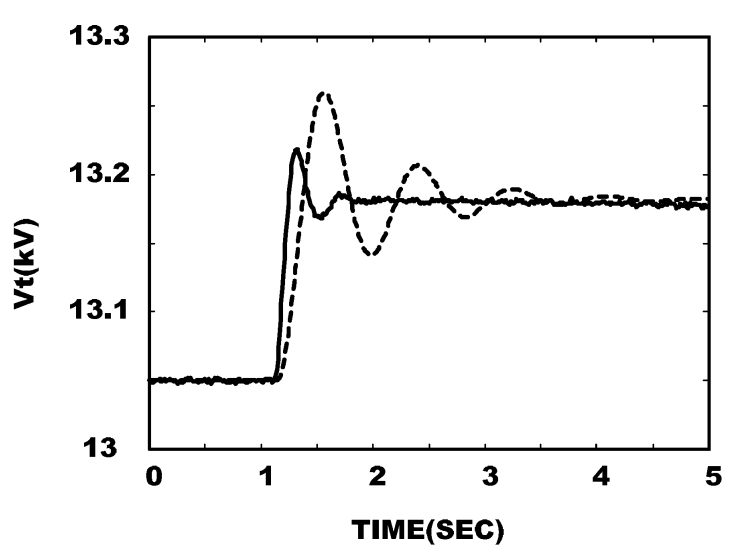

(a)

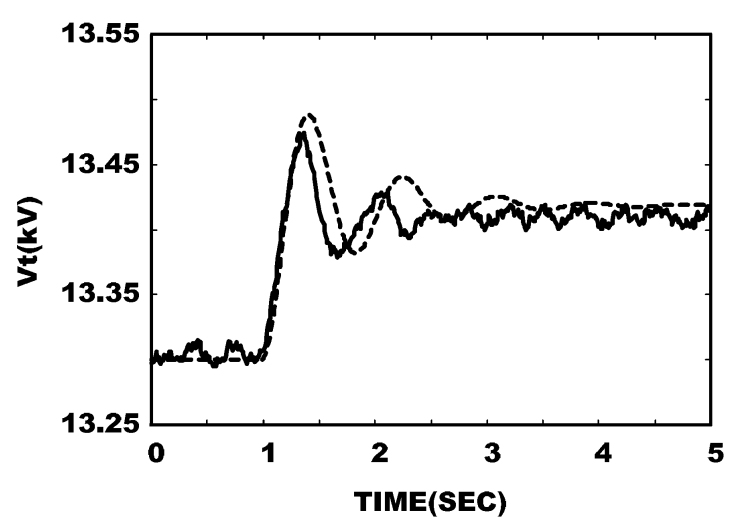

(b)

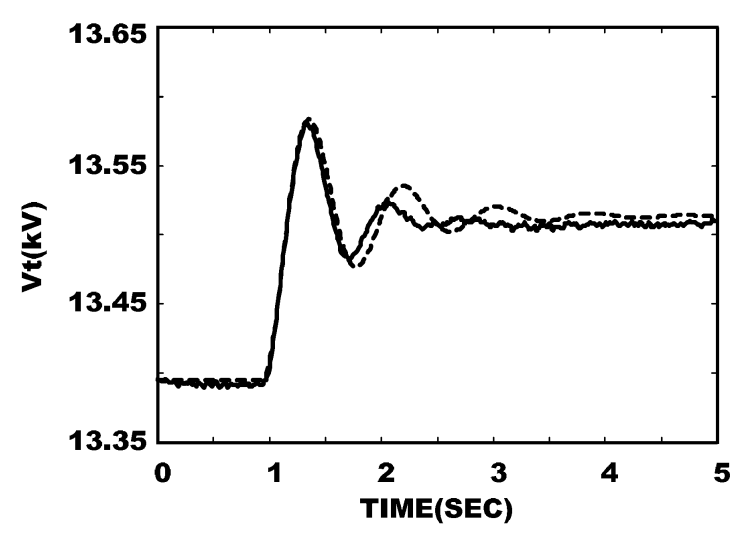

(c)

Thus, only the gain $K_{i n n}$ and time constant $T_{i n n}$ of the inner-loop in the firing-control circuit should be identified.

The least-squared-error algorithm is used. Three steps are taken:

(1) A 1\% step signal is injected into the SES in Fig. 2. A digital transient recorder is used to record input and output response data of the inner-loop.

(2) A low-pass filter is used to eliminate high frequency noises in recorded data.

(3) The least-squared-error algorithm is employed to identify $K_{i n n}$ and $T_{i n n}$ by providing a model to achieve a best fit to experimental data [2].

The responses of $v_{a v r}$ and $v_{i n n}$ in the inner-loop were recorded. The sampling time, $T_{s}$, is 0.347 milliseconds. The test time $T$ is 5 seconds. The total sampling point number is

$$
m=\frac{T}{T_{S}}
$$

For a sequence of m observations of $v_{i n n}$ and $v_{a v r}$, they can be expressed by $v_{i n n}(k+1), v_{i n n}(k)$, and $v_{a v r}(k), k=$ $1,2, \ldots \ldots \ldots, m$. There are $m$ linear equations.

$$
v_{\text {inn }}(k+1)=a_{1} v_{\text {avr }}(k)+a_{2} v_{\text {inn }}(k), k=1,2, \ldots \ldots, m
$$

Let $\overline{\mathbf{A}}=\left[\begin{array}{ll}a_{1} & a_{2}\end{array}\right]^{T}$ be a set of constant parameters, $a_{1}=K_{\text {inn }}\left(1-e^{-\frac{T_{S}}{T_{\text {inn }}}}\right)$ and $a_{2}=e^{-\frac{T_{S}}{T_{\text {inn }}}}$ to be estimated. In statistics literature, equation (8) is called a regression function, and $a_{1}$ and $a_{2}$ are the regression coefficients. The system of equation (8) can be conveniently arranged into a simple matrix form

$$
\overline{\mathbf{V}} \min =\overline{\mathbf{V}} \overline{\mathbf{A}}
$$

where

$$
\begin{gathered}
\overline{\mathbf{V}}_{\text {inn }}=\left[\begin{array}{c}
v_{i n n}(2) \\
v_{i n n}(3) \\
\vdots \\
v_{i n n}(m+1)
\end{array}\right] \\
\overline{\mathbf{V}}=\left[\begin{array}{cc}
v_{a v r}(1) & v_{\text {inn }}(1) \\
v_{a v r}(2) & v_{i n n}(2) \\
\vdots & \vdots \\
\vdots & \vdots \\
v_{a v r}(m) & v_{\text {inn }}(m)
\end{array}\right]
\end{gathered}
$$

Fig. 7. Generator voltage step responses with temporary setting of excitation system (a) generator 1-1; (b) generator 1-2; (c) generator 1-3.

It is necessary that $m \geq 2$. If $m=2$ and the inverse of $\overline{\mathbf{V}}$ exists, it can solve $\overline{\mathbf{A}}$ uniquely by 
Table 2. Dynamic performance indexes with temporary setting of excitation systems

\begin{tabular}{|c|c|c|c|c|c|}
\hline & & $\begin{array}{l}\text { Rise time } \\
\quad(\mathrm{sec})\end{array}$ & $\begin{array}{l}\text { Overshoot } \\
(\%)\end{array}$ & $\begin{array}{l}\text { Damping } \\
\text { ratio }\end{array}$ & $\begin{array}{l}\text { Settling } \\
\text { time (sec) }\end{array}$ \\
\hline \multirow{3}{*}{$\begin{array}{l}\text { Field } \\
\text { test }\end{array}$} & Generator 1-1 & 0.08 & 29.14 & 0.37 & 0.64 \\
\hline & Generator 1-2 & 0.14 & 61.37 & 0.15 & 1.46 \\
\hline & Generator 1-3 & 0.16 & 52.32 & 0.20 & 1.94 \\
\hline \multicolumn{2}{|c|}{ Computer simulation } & 0.15 & 58.46 & 0.17 & 1.49 \\
\hline \multicolumn{2}{|c|}{$\begin{array}{l}\text { IEEE-421.2 standard } \\
\text { recommendation }\end{array}$} & $0.1 \sim 2.5$ & $0 \sim 80$ & $0 \sim 1$ & $0.2 \sim 10$ \\
\hline \multicolumn{2}{|c|}{$\begin{array}{l}\text { Accepted range of a good feedback } \\
\text { control system [4] }\end{array}$} & - & $\leq 15$ & $\geq 0.6$ & - \\
\hline
\end{tabular}

$$
\overline{\mathbf{A}}=\overline{\mathbf{V}}^{-1} \overline{\mathbf{V}} \text { inn }
$$

However, when $m>2$, generally it is not possible to determine $\overline{\mathbf{A}}$ exactly to satisfy all equations because the data may be complicated by random measurement noises, errors in the model, or a combination of both. An alternative is to obtain the estimate, $\widehat{\hat{\mathbf{A}}}$, based on least error squares. Define an error vector $\overline{\mathbf{e}}=\left[\begin{array}{lll}\varepsilon_{1} & \varepsilon_{2} & \ldots\end{array}\right.$ $\left.\varepsilon_{m}\right]^{T}$, and let

$$
\overline{\mathbf{e}}=\overline{\mathbf{V}}_{\text {inn }}-\overline{\mathbf{V}} \overline{\mathbf{A}}
$$

The choice of $\hat{\mathbf{A}}$ is to minimize the objective function

$$
J=\sum_{i=1}^{m} \varepsilon_{i}^{2}=\overline{\mathbf{e}}^{\mathbf{T}} \overline{\mathbf{e}}
$$

It can be expressed as

$$
\begin{aligned}
J & =\left(\overline{\mathbf{V}}_{\text {inn }}-\overline{\mathbf{V}} \overline{\mathbf{A}}\right)^{T}\left(\overline{\mathbf{V}}_{\text {inn }}-\overline{\mathbf{V}} \overline{\mathbf{A}}\right) \\
& =\overline{\mathbf{V}}_{\text {inn }}^{\mathbf{T}} \overline{\mathbf{V}}_{\text {inn }}-\overline{\mathbf{A}}^{\mathbf{T}} \overline{\mathbf{V}}^{\mathbf{T}} \overline{\mathbf{V}}_{\text {inn }}-\overline{\mathbf{V}}_{\text {inn }}^{\mathbf{T}} \overline{\mathbf{V}} \overline{\mathbf{A}} \\
& +\overline{\mathbf{A}}^{\mathbf{T}} \overline{\mathbf{V}}^{\mathbf{T}} \overline{\mathbf{V}} \overline{\mathbf{A}}
\end{aligned}
$$

Differentiate $J$ with respect to $\overline{\mathbf{A}}$ and equate the result to zero, that is,

$$
\left.\frac{\partial J}{\partial \overline{\mathbf{A}}}\right|_{\bar{A}=\hat{A}}=-2 \overline{\mathbf{V}}^{T} \overline{\mathbf{V}} \text { inn }+2 \overline{\mathbf{V}}^{T} \overline{\mathbf{V}} \hat{\mathbf{A}}=0
$$

We have

$$
\overline{\mathbf{V}}^{T} \overline{\mathbf{V}} \hat{\mathbf{A}}=\overline{\mathbf{V}}^{T} \overline{\mathbf{V}} \text { inn }
$$

Then

$$
\hat{\mathbf{A}}=\left(\overline{\mathbf{V}}^{T} \overline{\mathbf{V}}\right)^{-1} \overline{\mathbf{V}}^{T} \overline{\mathbf{V}}_{\mathbf{i n n}}
$$

\section{IDENTIFICATION RESULTS}

In the parameter identification, 400 iterations are used. For generator 1-1, the iteration procedure of $K_{i n n}$, $T_{\text {inn }}$, and $J$ is shown in Fig. 8. The average value of $K_{\text {inn }}$ is $8.01, T_{i n n}$ and that of is 0.0516 second. The computer simulation response with identified $K_{i n n}$ and $T_{i n n}$ of generator 1-1 voltage is shown in Fig. 9. The result is similar with the field test response. The identified values of $K_{i n n}$ and $T_{i n n}$ of this generator are different with the temporary setting values. Table 3 also shows the identified parameters in the inner-loop of generators 1-2 and 1-3.

\section{RETUNING OF SES}

The SESs should be tuned again so that the dynamic performance can be better. Because the SES uses analog electronic circuit, it is easy to tune the elements in the automatic voltage regulator [14]. The values of $K_{i n n}$ and $T_{i n n}$ are given by the identified parameter values of generator 1-1. Then it is emphasized on the automatic voltage regulator $[5,6]$.

(1) The differential time constant $T_{C}$ is set to a standard value of 1 second.

(2) The integral time constant $T_{B}$ could be tuned from 1 to 12 seconds.

(3) The value of $K_{A}$ could be from 20 to 230 to have a proper whole system loop gain [4].

The performance indices with respect to $K_{A}$ and $T_{B}$ are shown in Fig. 10. From Figure $10, K_{A}=50$ and $T_{B}$ $=10$ seconds are suitable for the study system. The final parameter setting values are indicated in the fourth column of Table 1. The step change responses of generator voltage are shown in Fig. 11, where the damping is good as shown in Table 4. The field test is similar with the computer simulation. The SES with the final 


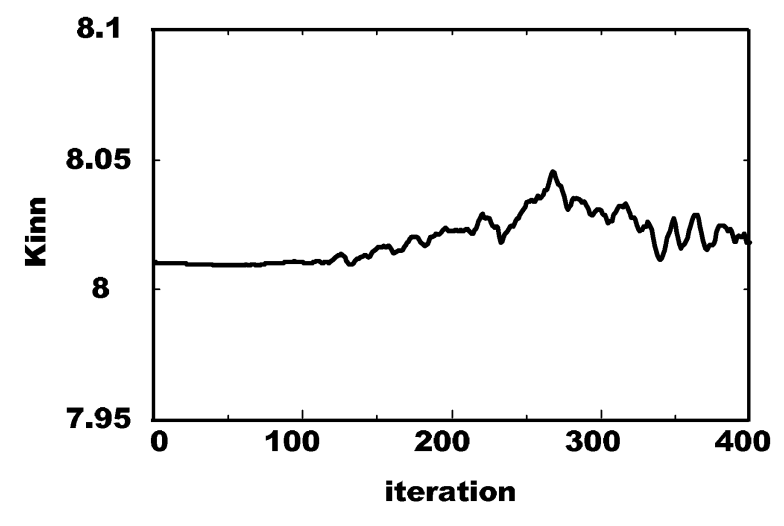

(a)

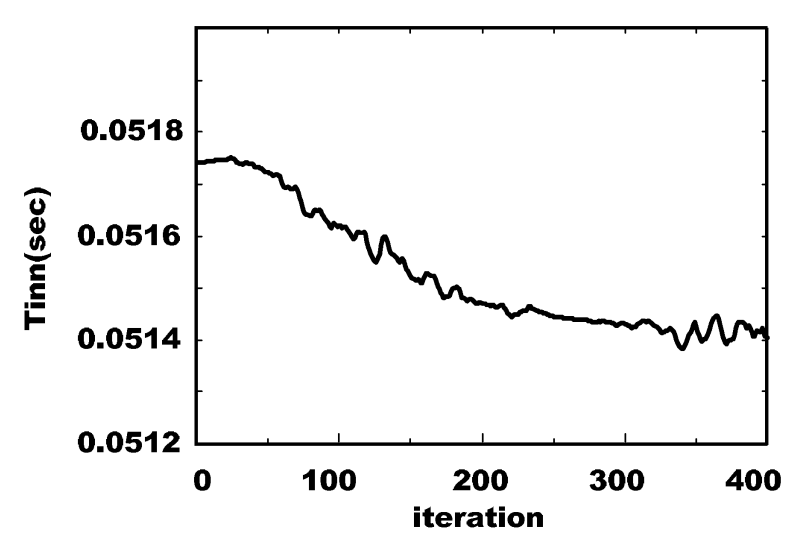

(b)

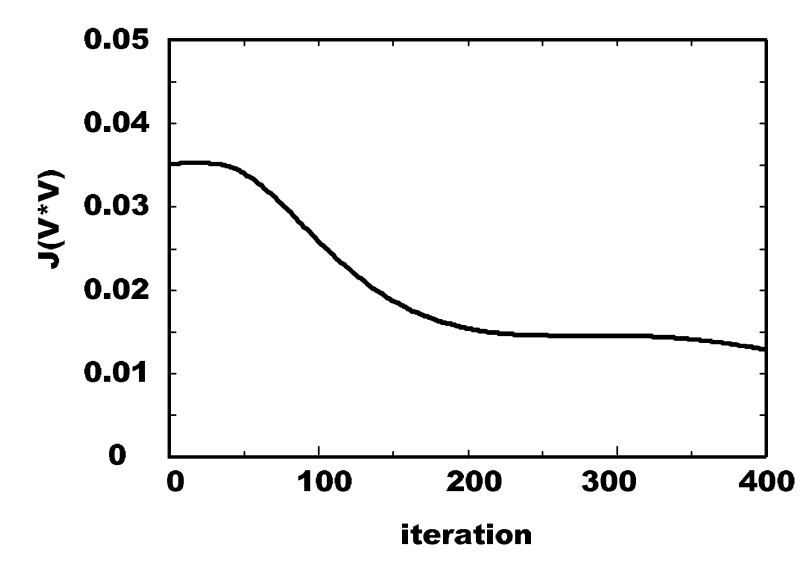

(c)

Fig. 8. Results during identifying SES parameters of generator 1-1 (a) Kinn; (b) Tinn; (c) objective function.
Table 3. Result of parameter identification in the inner-loop of excitation system

\begin{tabular}{l|cc}
\hline Parameters & Kinn & $\begin{array}{l}\text { Tinn } \\
(\mathrm{sec})\end{array}$ \\
\hline Generator & 8.01 & 0.0516 \\
Generator 1-1 & 8.42 & 0.26 \\
Generator 1-2 & 8.41 & 0.27 \\
\hline
\end{tabular}

Table 4. Dynamic performance indexes of generator 1-1 with final setting of excitation system

\begin{tabular}{lcccc}
\hline & $\begin{array}{c}\text { Rise time } \\
(\mathrm{sec})\end{array}$ & $\begin{array}{c}\text { Overshoot } \\
(\%)\end{array}$ & $\begin{array}{c}\text { Damping } \\
\text { ratio }\end{array}$ & $\begin{array}{c}\text { Settling } \\
\text { time }(\mathrm{sec})\end{array}$ \\
\hline Simulation & 0.2 & 8.9 & 0.61 & 2.25 \\
Field test & 0.3 & 9 & 0.6 & 2.6 \\
\hline
\end{tabular}

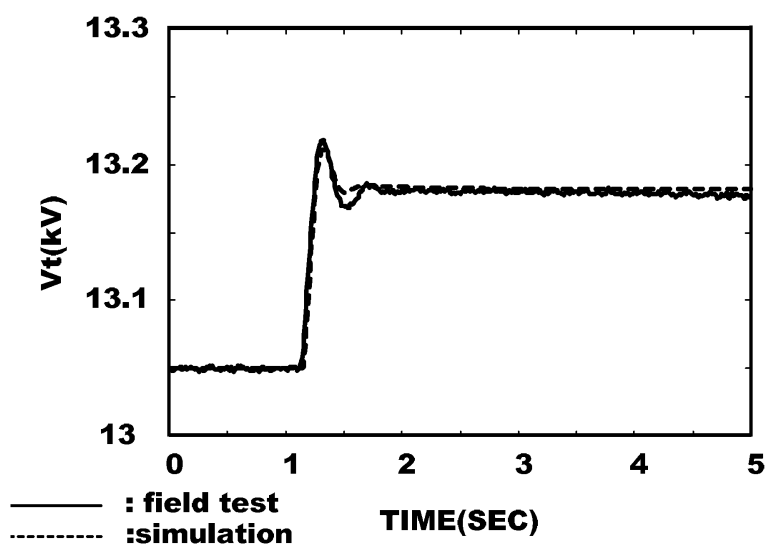

Fig. 9. Generator voltage step response of generator 1-1 after parameters identification of excitation system.
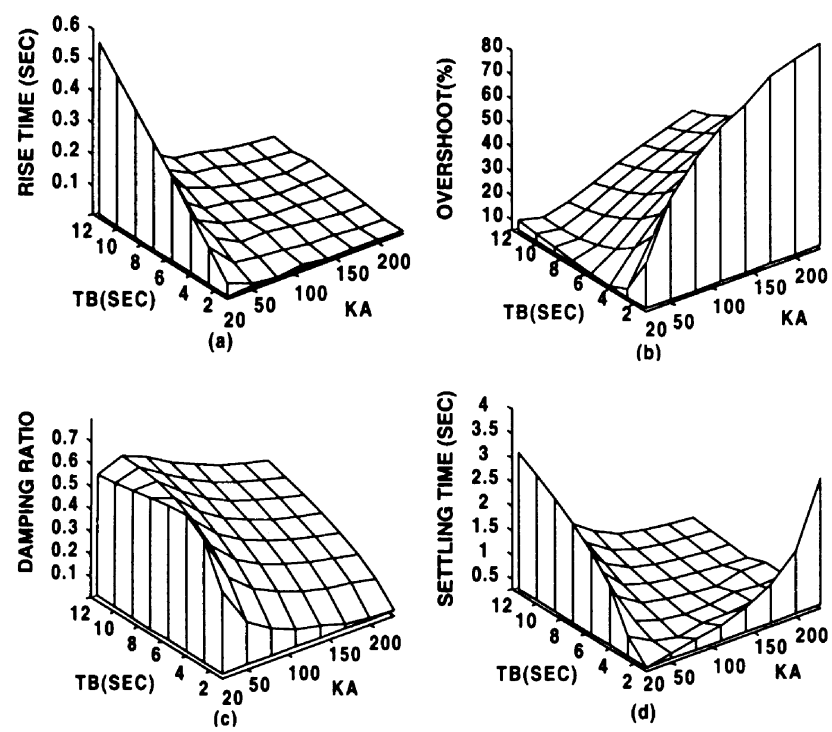

Fig. 10. Changing of dynamic performance indexes (a) rise time; (b) overshoot; (c) damping ratio; (d) settling time. 
parameter setting could be a good feedback control system. The same tuning procedures are used to other ST generators in units 1 and 2.

To examine the dynamic stability of a generator under load, a two-axis model and an SES could be used. Since the rating of each GT generator is much smaller than the short circuit capacity of the $161-\mathrm{kV}$ bus, and each generator is connected to that bus by a separate transformer, the generator can be assumed to be connected to an infinite-bus through a step-up transformer and a transmission line with line reactance Xe. The generator and the transformer data are given in the Appendix.

The changing of eigenvalues of electromechanical and exciter modes considering generator active power $P$ from 0.2 to 0.75 , reactive power $Q$ from 0 to 0.35 , and transmission reactance $\mathrm{Xe}$ from 0 to 0.35 are shown in Fig. 12. Some operating conditions with original or temporary parameter setting may be unstable. Table 5 shows the eigenvalues of the generator system under light and full load conditions. Since the generator rating is large than the gas turbine, the active power loading at 0.52 is said to be full load. At light load and full load, the final parameter setting gives a system with better damping in the electromechanical mode to depress power oscillations. It is desired to examine the transient behavior of the generator to demonstrate the eigenvalues. The time domain computer simulation results for a $5 \%$ step change of the mechanical power as a small disturbance are shown in Fig. 13. It reveals that the final parameter setting of SES ensures a system with better dynamic stability.

\section{CONCLUSION}

This paper gives a comprehensive experience about

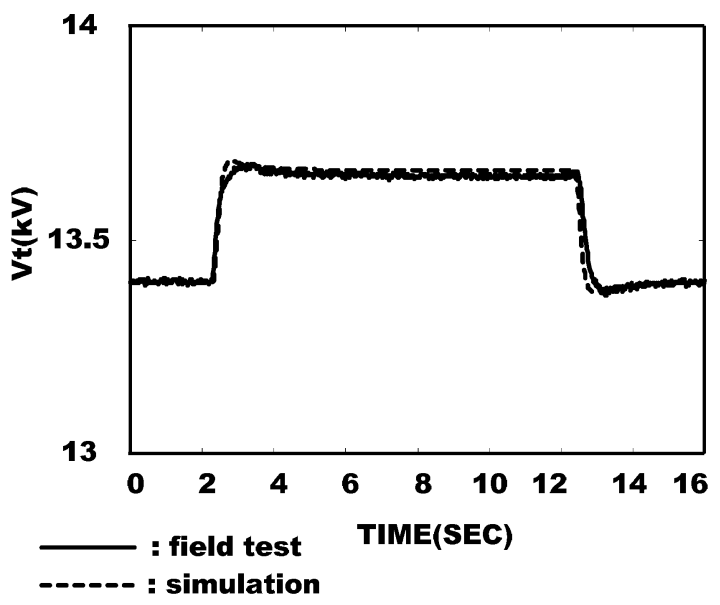

Fig. 11. Generator voltage step response of generator 1-1 with final setting of excitation system.

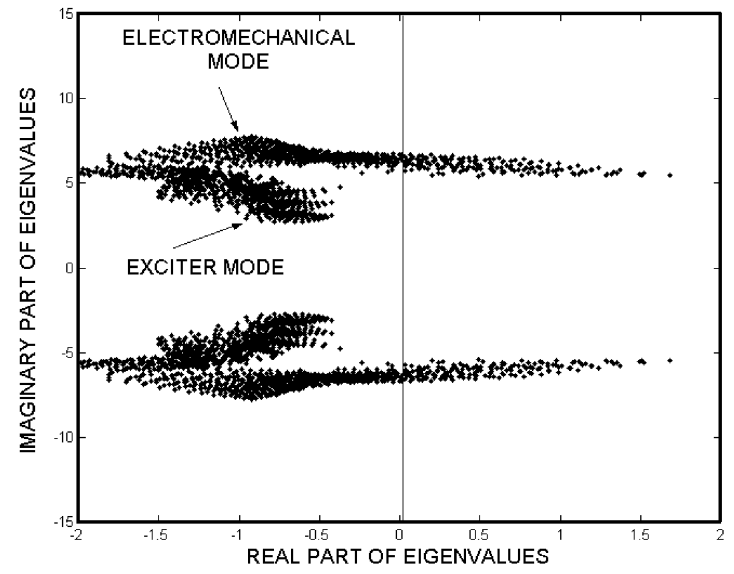

(a)

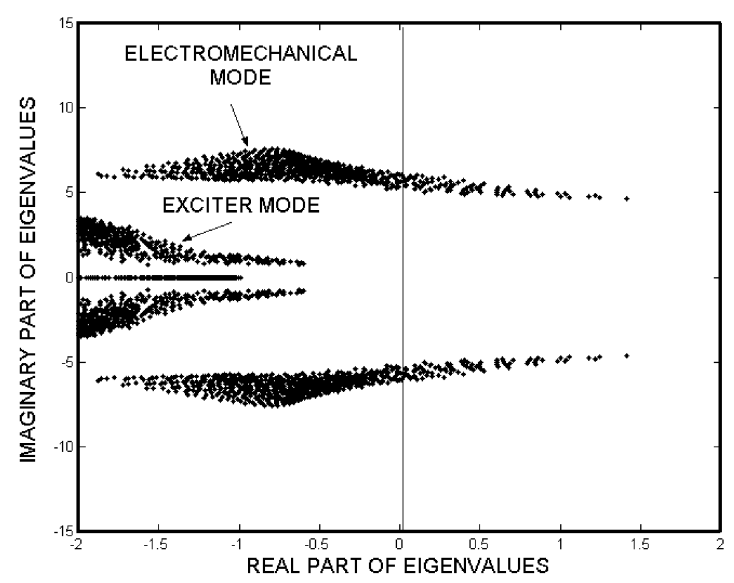

(b)

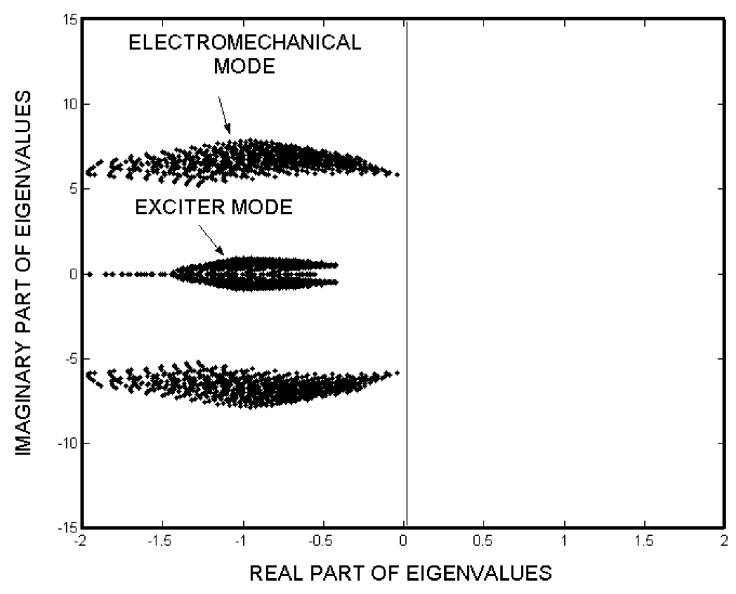

(c)

Fig. 12. Eigenvalues of generator system with different parameter setting of excitation system (a) original setting; (b) temporary setting; (c) final setting. 
Table 5. Eigenvalues of generator system

\begin{tabular}{|c|c|c|c|}
\hline $\begin{array}{l}\text { Parameters of } \\
\text { excitation } \\
\text { system }\end{array}$ & Original setting & Temporary setting & Final setting \\
\hline $\begin{array}{c}\text { Light load } \\
(P=0.2, Q=0.05)\end{array}$ & $\begin{array}{l}-999.98 \\
-333.54 \\
-6.9 \\
-1.02 \\
-1.35 \pm \mathrm{j} 6.83^{*} \\
-2.15 \pm \mathrm{j} 4.56^{+}\end{array}$ & $\begin{array}{l}-999.99 \\
-333.44 \\
-7.02 \\
-1.05 \\
-1.24 \pm \mathrm{j} 5.84^{*} \\
-2.18 \pm \mathrm{j} 3.48^{+}\end{array}$ & $\begin{array}{l}-999.98 \\
-333.5 \\
-17.78 \\
-8.14 \\
-1.53 \pm \mathrm{j} 5.58^{*} \\
-1.13 \pm \mathrm{j} 0.48^{+}\end{array}$ \\
\hline $\begin{array}{c}\text { Full load } \\
(P=0.52, Q=0.05)\end{array}$ & $\begin{array}{l}-999.98 \\
-333.48 \\
-8.69 \\
-1.06 \\
-0.09 \pm \mathrm{j} 6.54^{*} \\
-2.52 \pm \mathrm{j} 4.9^{+}\end{array}$ & $\begin{array}{l}-999.99 \\
-333.41 \\
-8.87 \\
-1.14 \\
-0.44 \pm \mathrm{j} 6.31^{*} \\
-2.02 \pm \mathrm{j} 3.31^{+}\end{array}$ & $\begin{array}{l}-999.99 \\
-333.45 \\
-18.36 \\
-9.94 \\
-0.65 \pm j 6.53^{*} \\
-0.84 \pm j 0.75^{+}\end{array}$ \\
\hline
\end{tabular}

\footnotetext{
*: Electromechanical mode; +: Exciter mode.
}

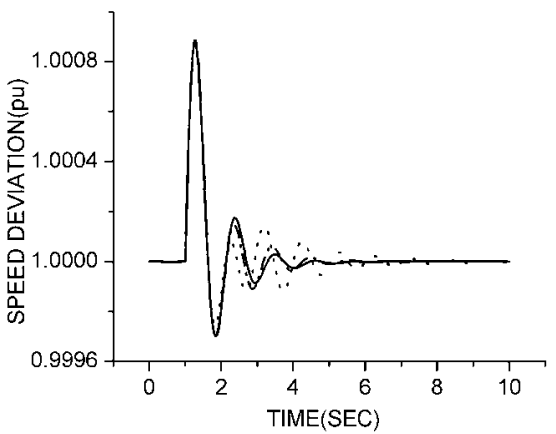

(a)

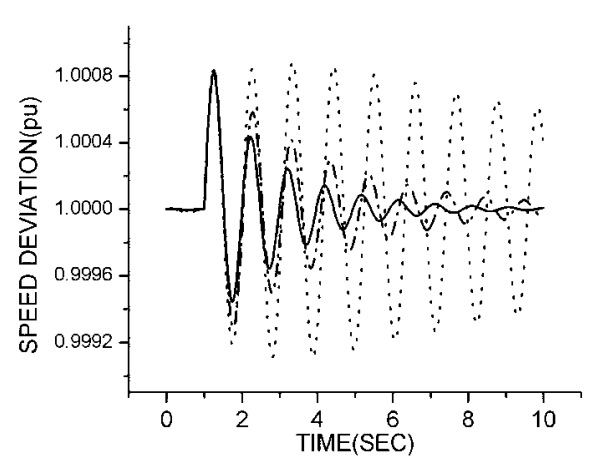

(b)

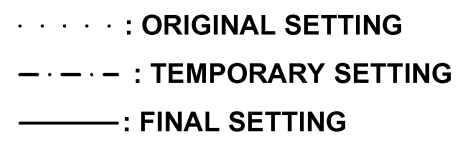

Fig. 13. Generator speed response to a $5 \%$ mechanical power change (a) light load; (b) full load. the dynamic performance improvement of excitation systems and dynamic stability enhancement of synchronous generators. The method by injecting a step signal into the excitation system is a good approach to assessing the dynamic performance condition of generator voltage response. The least-squared-error algorithm is also useful to identify the parameters of excitation systems. The stability of gas turbine generators has been ensured and the parameter values of excitation systems are accurate. The SESs have been retuned again to have good dynamic performance indices to confirm in the range of a good feedback control system. It is concluded that the generators with SESs in Tong-Shiao Generation Station should have been satisfactorily tuned to have enough damping of power oscillations.

\section{ACKNOWLEDGMENTS}

The authors would like to express their sincere thanks to people in Tong-Shiao Generation Station for help in this work.

\section{REFERENCES}

1. General Electric, Potential Source Excitation System for Gas Turbine, General Electric Company, Virginia, U.S. A. (1985).

2. Hsia, T.C., System Identification: Least Squares Methods, Lexington Book, Lexington, Massachusetts, U.S. A. (1977).

3. IEEE, IEEE Standard Definition for Excitation System for Synchronous Machines, Standard 421.1, New York, U.S.A. (1986). 
4. IEEE, IEEE Guide for Identification, Testing, and Evaluation of The Dynamic Performance of Excitation Control System, Standard 421.2, New York, U.S.A. (1990).

5. Koessler, R.J., "Techniques for Tuning Excitation System Parameters," IEEE Trans. Energy Convers., Vol. 3, pp. 785-791 (1988).

6. Kundur, P., Klein, M., Rogers, G.J., and Zywno, M.S., "Application of Power System Stabilizers for Enhancement of Overall System Stability," IEEE Trans. Power Syst., Vol. 4, pp. 614-626 (1989).

7. Lawrence, P.J. and Pogers, G.J., "Sequential Transferfunction Synthesis from Measured Data," IEE Proc., Vol. 126, pp. 104-106 (1979).

8. Liou, T.S., Liou, Y.S., and Chang, J.L., "Measurement and Analysis of Dynamic Response of Excitation System for TPC Generation Units," Taipower, PRI Res. Report, Taiwan, R.O.C. (1993).

9. Liu, C.S., Hsu, Y.Y., Jeng, L.H., Lin, C.J., Huang, C.T., Liu, A.H., and Li, T.H., "Identification of Exciter Constants Using a Coherence Function Based Weighted Least Squares Approach," IEEE Trans. Energy Convers., Vol. 8, pp. 460-467 (1993).

10. Machowski, J., Bialek, J.W., Robak, S., and Bumby, J.R., "Excitation Control System for Use with Synchronous Generators," IEE Proc. C, Vol. 145, pp. 537-546 (1998).

11. Merchant, R.W. and Gibbard, M.J., "Identification of Synchronous Machine Parameters from Standstill Tests Using Recursive Estimation with the Bilinear
Operator," IEE Proc. C, Vol. 139, pp. 157-165 (1992).

12. Tumageanian, A. and Keyhani, A., "Identification of Synchronous Machine Linear Parameters from Standstill Step Voltage Input Data," IEEE Trans. Energy Convers., Vol. 10, pp. 232-240 (1995).

13. Wrate, C.A. and Wozniak, L., "Hydrogenerator System Identification Using a Simple Genetic Algorithm," IEEE Trans. Energy Convers., Vol. 12, pp. 60-65 (1997).

14. Wu, C.J., Yen, S.S., Chang, W.N., and Guo, T.Y., "Enhancement of Static Excitation System Performance for Generators Near Electric Arc Furnace Loads," IEEE Trans. Energy Convers., Vol. 14, pp. 225-231(1999).

15. Zhao, Z., Xu, L., and Jiang, J., "On-line Estimation of Variable Parameters of Synchronous Machines Using a Novel Adaptive Algorithm-principles and Procedures," IEEE Trans. Energy Convers., Vol. 12, pp. 193-199 (1997)

\section{APPENDIX}

System data (pu, except as indicated)

The two-axis model describes the generator. The parameters are obtained from the machine manual [1]. The base values are $115.75 \mathrm{MVA}$ and $13.8 \mathrm{kV}$.

Generator: $\mathrm{Xd}=2.599 ; \mathrm{Xq}=2.504 ; \mathrm{X}^{\prime} \mathrm{d}=\mathrm{X}^{\prime} \mathrm{q}=$ $0.513 ; \mathrm{T}^{\prime} \mathrm{do}=3.163 \mathrm{sec}$

T'qo $=0.339 \mathrm{sec} ; \mathrm{Ra}=0.006 ; \mathrm{H}=4.76 \mathrm{sec}$

Exciter: $\mathrm{V} \max =7.3 ; \mathrm{Vmin}=-7.3$

Transformer: $\mathrm{Xtr}=0.15$ 